\title{
Feasibility Investigation of Direct Laser Cutting Process of Metal Foam with High Pore Density
}

\author{
Yangxu Liu ${ }^{1}$, Wei Zhou ${ }^{1 *}$, Xuyang Chu ${ }^{1}$, Shaoyu Liu ${ }^{1}$, Kwan San Hui ${ }^{2}$ \\ ${ }^{1}$ Department of Mechanical \& Electrical Engineering, Xiamen University, Xiamen 361005, China \\ ${ }^{2}$ School of Mathematics, University of East Anglia, Norwich, NR4 7TJ, United Kingdom
}

\begin{abstract}
To avoid damage to the pore structure of metal foam, a laser cutting process for efficiently and directly cutting metal foam into regular shapes is proposed. After analyzing the proposed laser cutting process, its effects when applied to three different types of metal material (copper, ferroalloy, and nickel) and two levels of pore density, namely 90 and 110 pores per inch (PPI), were investigated. The results show that metal foam with a good surface quality can be obtained without damaging the pore structure by using the proposed laser cutting process. Of the three metal types considered, the highest material removal rate (MRR) and material oxidation rate (MOR) were observed for ferroalloy foam. Of the two pore densities, metal foam of 90 PPI showed a larger material removal rate than metal foam of 110 PPI. The MRR and MOR increased with an increase in the laser output power and decrease in the scanning speed. Using a central composite experimental design method, optimized processing parameters of $26 \mathrm{~W}$ laser output power and $475 \mathrm{~mm} / \mathrm{s}$ scanning speed were adopted to cut the metal foam with a high pore density.
\end{abstract}

Keywords: Metal foam; Laser cutting; Material removal rate; Material oxidation rate

\footnotetext{
*Corresponding author. Tel.: 86-592-2188698; Fax: 86-592-2186383

E-mail address: weizhou@xmu.edu.cn (Wei Zhou).
} 


\section{Introduction}

During the last three decades, different types of metal foam with a high pore density and three-dimensional pore structure have been developed using different manufacturing methods. The many outstanding properties of metal foam, such as its low density, high gas permeability, high specific surface area, good energy absorption characteristics, and high thermal conductivity, make it an attractive material for use in various industrial applications. Some types of metal foam, including copper foam, ferroalloy foam, nickel foam, and aluminum foam, are fabricated at a large scale with different characteristics. For example, copper foam has high thermal conductivity, which can be used as a thermally conductive material [1]. Ferroalloy foam has a high impact resistance and good energy absorbing characteristics, and has been used in the transportation industry as a damping material [2]. Nickel foam has good electromagnetic shielding properties, and has been used as an electromagnetic shielding material [3]. These metal foam types are considered preferred materials for catalyst supports because their highly specific surface area provides more opportunities for contact with gas or liquids as catalysts in a microreactor. Microreactors with metal foam as a catalyst support have also been studied, such as in the steam reforming of methanol [4], mass-transfer characterization, and catalyst loading method $[5,6]$. In addition, metal foam can be used as a type of bio-material, and its various $3 \mathrm{D}$ porous surfaces or structures that are able to be created can enhance the biological fixation on orthopedic implants [7].

Based on the pore structure, metal foam can be divided into two types: 
closed-cell [8] and open-cell [9] types. For closed-cell metal foam, the pores are not connected to each other. However, each pore is connected with each other in open-cell metal foam. The typical porosity of metal foam with an open cell ranges from $80 \%$ to 90\%. Furthermore, the cell size of metal foam is commonly given in pores per linear inch (PPI), which are typically used to characterize the porosity [10]. Metal foam have been developed using different manufacturing methods, the most common of which is a foaming method [11]. Other fabrication methods of metal foam are also used, including the metallurgy process $[12,13]$, deposition [14], and permeation [15]. A large number of studies have been conducted on the development and establishment of fabrication processes to produce metal foam at low cost. However, owing to its wide range of applications, extensive requirements for metal foam with a regular shape and accurate size are necessary. The greatest challenge to generating metal foam is the follow-up process used to control the cell structure. A traditional cutting method can cause a pore collapse, plastic deformation, and/or interface stripping, which limit a high degree of freedom in the engineering design and prospective application of the metal foam [16].

Recently, there have been a few studies focusing on electrical discharge machining (EDM) for the cutting of metal foam. For example, Scott et al. [17] used EDM to cut both Fe-Cr-Al alloy foam and 316 stainless steel foam, and investigated the effects of the feeding speed and spark on-time ratio on the material removal rate (MRR). Their results show that the MRR is positively correlated with the feed speed and discharge duration, and is inversely related to the discharge cycle. Alexander et al. 
[18] investigated the influence of the mesostructured parameters of aluminum foam on the EDM process. The results show that very fast feed speeds can be achieved through good flushing conditions and a low relative density of the material. Extensive experiments using EDM were conducted on solid stainless steel and porous stainless steel with different pore sizes [19]. MRR and the tool wear ratio were used to evaluate the machining performance of micro EDM. The relationship between the pore size and machining performance of EDM was revealed experimentally and through a numerical analysis. In summary, we found that EDM can effectively cut metal foam without causing a collapse or fracture of the pore structure, and can reduce the surface roughness by adjusting the processing parameters. However, the cutting speed of EDM is relatively slow and the cost is quite high. Moreover, a cooling liquid should be added for the machining process of EDM, in which the pores are easily blocked with residual impurities, which are difficult to clean.

From the above research results, we can see that a new cutting technology for metal foam urgently needs to be developed to meet the demands of different applications. In this study, a new direct laser cutting technology is proposed to rapidly cut metal foam of different materials and PPI. The direct laser cutting mechanism for metal foam is analyzed, and the effects of the laser processing parameters such as the laser output power and scanning speed on the MRR and the material oxidation rate (MOR), are further discussed. Finally, a central composite design (CCD) experiment conducted to optimize the laser processing parameters is described. 


\section{Experimental Methods and Devices}

Two levels of experiments were conducted to study the direct laser cutting process of metal foam: a single factor experiment and an experiment based on the CCD method. The influences of the laser output power and scanning speed on the MRR and MOR were investigated using a single factor experiment. The optimized laser processing parameters for metal foam were obtained using CCD.

Single factor experiment. The specific processing and testing process of metal foam are as follows: First, the metal foam was completely cut using a laser, and a series of rectangular metal foam shapes were obtained with a size of $30 \mathrm{~mm} \times 15 \mathrm{~mm}$ $\times 3 \mathrm{~mm}$. The topography of the cutting section of the metal foam was analyzed using a scanning electron microscope (SEM), and compared to traditional machining (milling process using a lathe). Second, three processing times (5, 10, and $15 \mathrm{~s}$ ) were preset for the different metal foam. Using various laser cutting parameters, different kerfs were fabricated on the surface of the metal foam. The depths of the kerfs were then measured to calculate the MRR of the metal foam. Finally, the cutting sections of the metal foam were analyzed using energy dispersive spectroscopy (EDS) to determine the MOR. A schematic of the cutting and detection process of metal foam is shown in Fig. 1. Using the same laser cutting parameters, the average oxygen mole ratio of three regions of the metal foam was considered as the MOR. In this paper, the MRR is defined as the processing depth of the kerfs per unit of time, which can be used to estimate the cut-off time of the metal foam. The MOR is defined as the 
difference in oxygen mole ratio before and after processing, which can be calculated through the following equations:

$$
\begin{aligned}
& R_{M}=\frac{D}{T} \\
& R_{\mathrm{o}}=C_{\mathrm{a}}-C_{\mathrm{b}}
\end{aligned}
$$

where $D$ is the depth of the kerf, $\mathrm{T}$ is the laser processing time, and $C_{\mathrm{a}}$ and $C_{\mathrm{b}}$ are the oxygen mole ratios of foam metal after and before the laser processing, respectively.

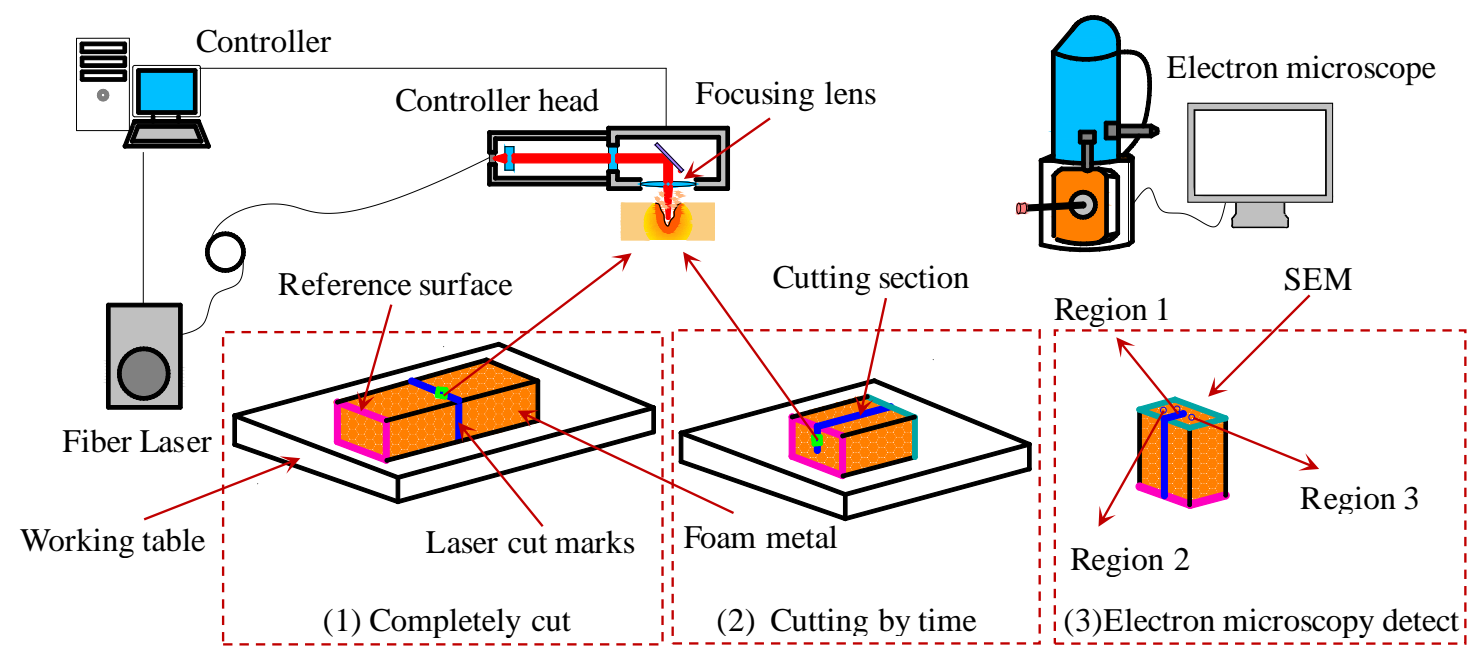

Fig. 1 Schematic of cutting and detection process of metal foam

Laser processing devices. The system is composed of a fiber laser, scanning galvanometer, focusing lens, computer-controlled system, power equipment, and worktable. In this study, a prototype pulsed fiber laser (IPG, No. YLP-1-100-20-20-CN, Germany) was used as the fabrication laser. The laser was set to produce $100 \mathrm{~ns}$ pulses with a $1064 \mathrm{~nm}$ central emission wavelength at a repetition rate of $20 \mathrm{kHz}$. The specifications of the characteristic parameters of the fiber laser system used are given in Table 1 . The pulse energy $\left(E_{\text {pulse }}\right)$ and peak power $\left(P_{\text {peak }}\right)$ can be calculated as [20] 


$$
\begin{array}{r}
E_{\text {pulse }}=\frac{P_{\text {average }}}{F_{\text {repetition }}} \\
P_{\text {peak }}=\frac{P_{\text {average }}}{F_{\text {repetition }} T_{\text {duration }}}
\end{array}
$$

where $P_{\text {average }}$ is the output power given by the laser source at a fixed frequency,

$F_{\text {repetion }}$ is the repetition rate, and $T_{\text {duration }}$ is the pulse duration.

Metal foam as a processed material was fixed to the worktable and a linear motor was used to move the laser head in the z-direction, allowing the laser beam to be focused on the surface of the sample materials by setting the focal length. Metal foam materials with $3 \mathrm{~mm}$ thickness and two different PPI (90 and110) were used, namely, copper foam, ferroalloy foam, and nickel foam, the specific chemical compositions of which are shown in Table 2. The preset width of the cut was $0.01 \mathrm{~mm}$, and an optical image of the direct laser cutting process is shown in Fig. 2.

Table 1 Specifications of characteristic parameters of the fiber laser system applied ${ }^{[21]}$

\begin{tabular}{cccc}
\hline Characteristic & Parameter range & Process conditions & Unit \\
\hline Wavelength & $1055-1070$ & 1064 & $\mathrm{~nm}$ \\
Beam quality $\left(\mathrm{M}^{2}\right)$ & $<1.1$ & 1 & $/$ \\
Incident beam diameter & $6-9$ & 7 & $\mathrm{~mm}$ \\
Focused diameter & $24.3-37.3$ & 31.5 & $\mathrm{um}$ \\
Laser output power & $0-30$ & $20-30$ & $\mathrm{~W}$ \\
Scanning speed & $0-1000$ & $200-800$ & $\mathrm{~mm} / \mathrm{s}$ \\
Repetition rate & $20-200$ & 20 & $\mathrm{KHz}$ \\
Nominal average output power & $19-21$ & 20 & $\mathrm{~W}$ \\
Pulse duration & $90-120$ & 100 & $\mathrm{~ns}$ \\
\hline
\end{tabular}

Table 2 Pore size and chemical composition of foam metals

\begin{tabular}{ccccc}
\hline Materials & Pore size $(\mathrm{mm})$ & \multicolumn{3}{c}{ Chemical compositions (molar ratio) } \\
\hline Copper foam & $0.2-0.4$ & $\mathrm{Cu}: 86.93 \%$ & O: $4.74 \%$ & C: $8.32 \%$ \\
ferroalloy foam & $0.2-0.4$ & Fe: $84.35 \%$ & O: $2.87 \%$ & C: $12.78 \%$ \\
nickel foam & $0.2-0.4$ & Ni: $87.25 \%$ & O: $3.17 \%$ & C: $9.58 \%$ \\
\hline
\end{tabular}




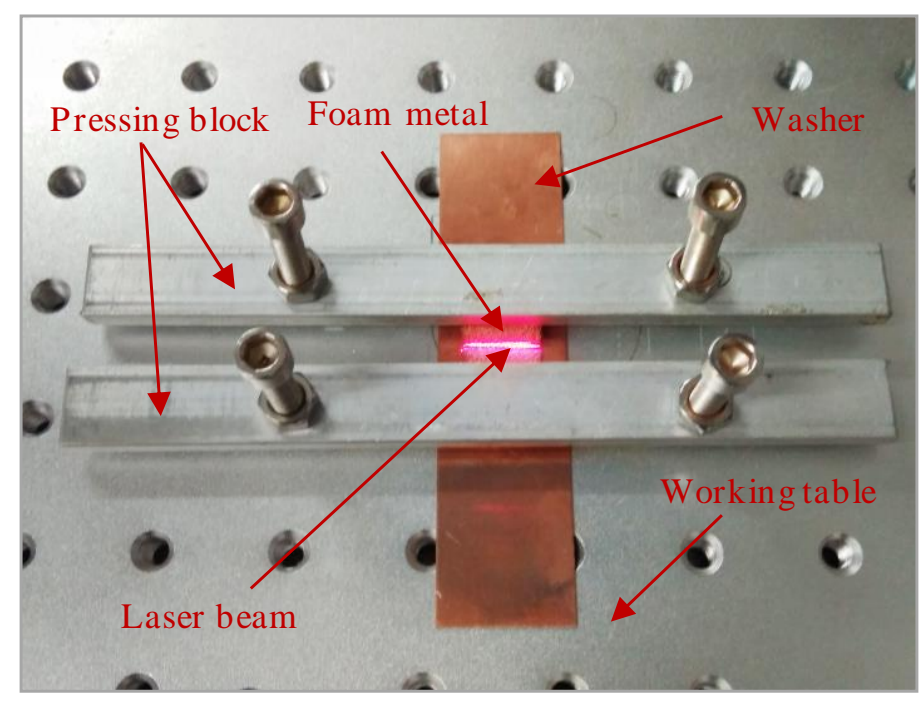

Fig. 2 Optical image of laser direct cutting process of metal foam

Central composite experiment design (CCD). The scanning speed and laser output power are independent variables, and the MRR and MOR are the targets. Regression equations can be established through the CCD to obtain the optimal parameters. The control factors and their levels are listed in Table 3. These experiments can be divided into three types: two level experiments of the axial points $\boldsymbol{0}$, experiments of asterisk $\star$, and zero horizontal experiments of the center $\mathrm{O}$, as shown in Fig. 3.

Table 3 Parameters of central composite experimental design

\begin{tabular}{cccc}
\hline Symbols & Factors & Level 1 & Level 2 \\
\hline $\mathrm{P}$ & Laser output power & $20 \mathrm{w}$ & $30 \mathrm{w}$ \\
$\mathrm{S}$ & Scanning speed & $200 \mathrm{~mm} / \mathrm{s}$ & $800 \mathrm{~mm} / \mathrm{s}$ \\
\hline
\end{tabular}




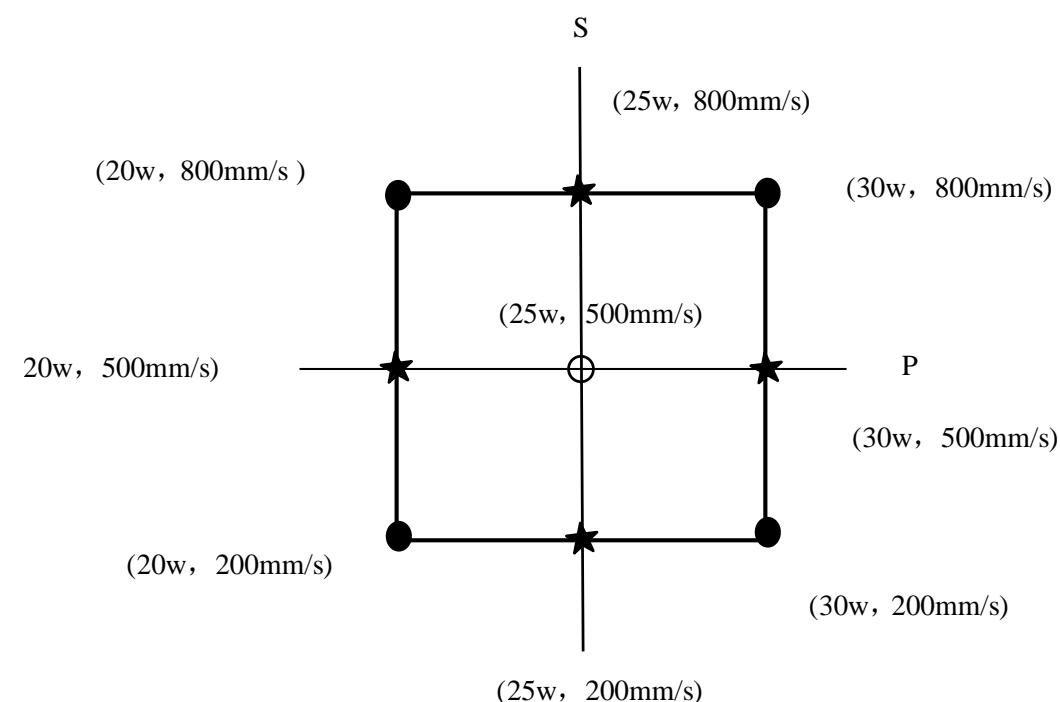

Fig. 3 Schematic of the central composite experimental design

\section{Results and Discussion}

\subsection{Laser cutting process of metal foam}

A schematic of the laser cutting process of metal foam is shown in Fig. 4. The laser cutting process of metal foam has the following three stages. In the initial stage of the cutting process, when the laser starts to radiate the surface of the metal foam, the majority of laser energy is absorbed by the foam. Later, the surface temperature of the metal foam increases quickly but the walls are not molten or gasified. As time goes on, the temperature reaches the melting point of the metal foam, and the walls of the metal foam begin to melt. A molten pool is formed in the area radiated by the laser. When the laser radiation period is further increased, the surfaces of the metal foam are gasified and plasma of a higher ionization is formed. The removal capability is greatly enhanced. In this way, the surface of the metal foam is successfully cut, as shown in Fig. 4(a). During the middle stage of the cutting process, with an increasing depth of 
the kerf, the removal efficiency is decreased because of the shielding of the laser beam. However, metal foam made using a foaming method has a porous structure, low density, impurities, and a rough surface. These characteristics give the metal foam a stronger laser absorption rate [22] and transmittance [23] than solid metal. Consistent with solid metal, the kerf surface of metal foam is affected by the laser cutting process, which is mainly reflected in the pits, wave stripes, and falling particles on the surface of the kerf [24, 25], as shown in Fig. 4(b). As the processing continues, the metal foam can be cut off during the final stage of the cutting process, as shown in Fig. 4(c). A kerf with a trapezoid shape can be obtained.

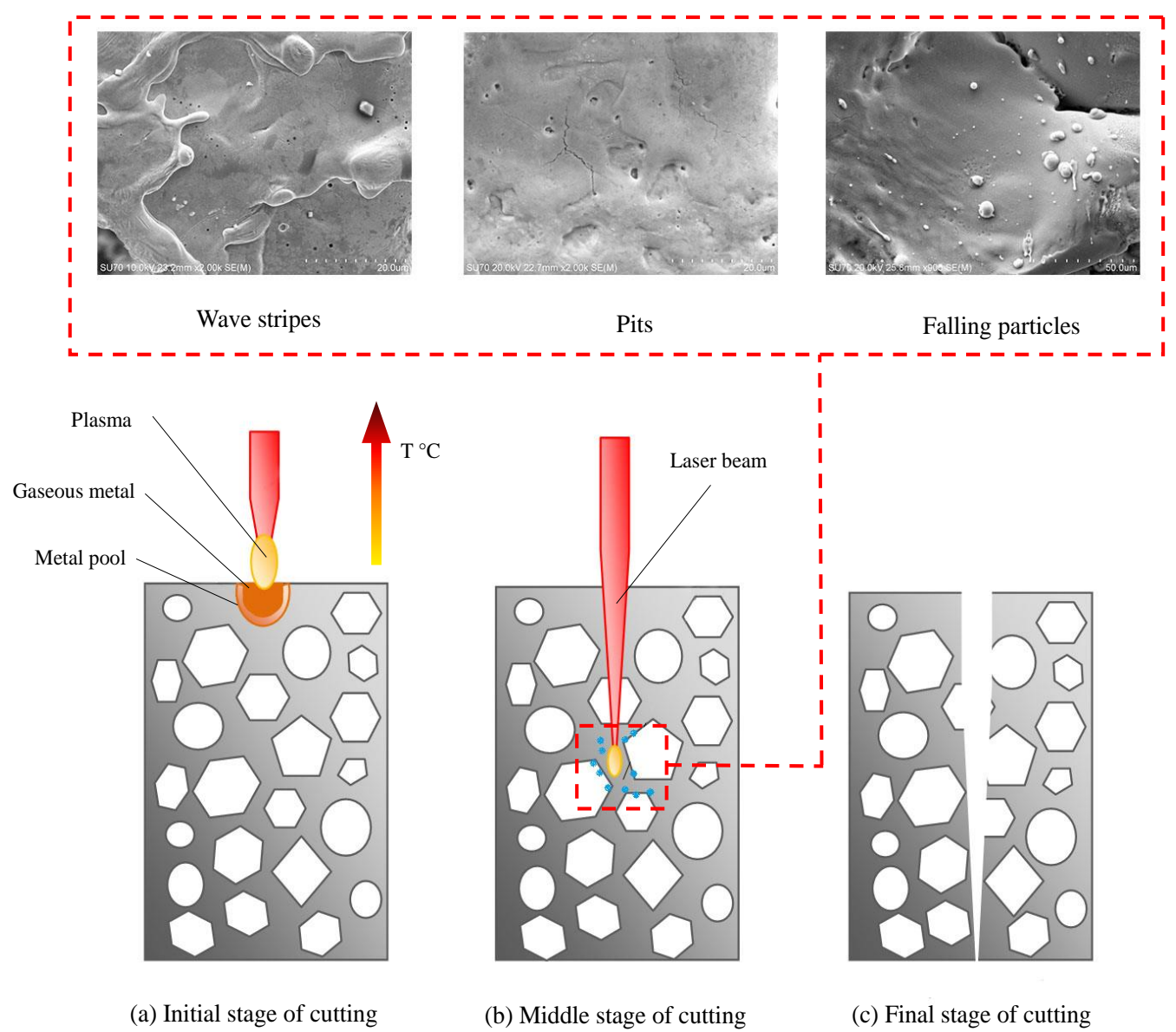

Fig.4 Schematic of laser cutting process of metal foam 
The SEM images of the kerf of metal foam using the proposed laser cutting process are shown in Fig. 5. Two fracture forms were found during the laser cutting process of metal foam. In one, the laser irradiates the wall of a single pore cell, destroying the cell; however, this does not affect the structure of the remaining pore cells, as shown in Fig. 5(a). In the other, the laser irradiates the middle walls of two pore cells. A kerf is created on the wall between the two pore cells and does not affect the other walls of the pore cells, ensuring the integrity of the pores, as shown in Fig. 5(c). A kerf with a trapezoid shape can be observed in Fig. 5(d). Furthermore, the width of the kerf is $24.5 \mu \mathrm{m}$, which is wider than the preset width. This can be attributed to the laser with high energy causing a thermal expansion of the metal foam. In addition, metal foam has a low density, with a structure that is not as tight as solid metal, and it is therefore more likely to burst when heated [26]. From Fig. 5(e), some tiny holes appear on the kerf surface of the metal foam. The reason for this may be attributed to the metal foam being made from foam technology and certain impurities. Bubbles are created through a physicochemical reaction of these impurities during the laser cutting process [27]. 

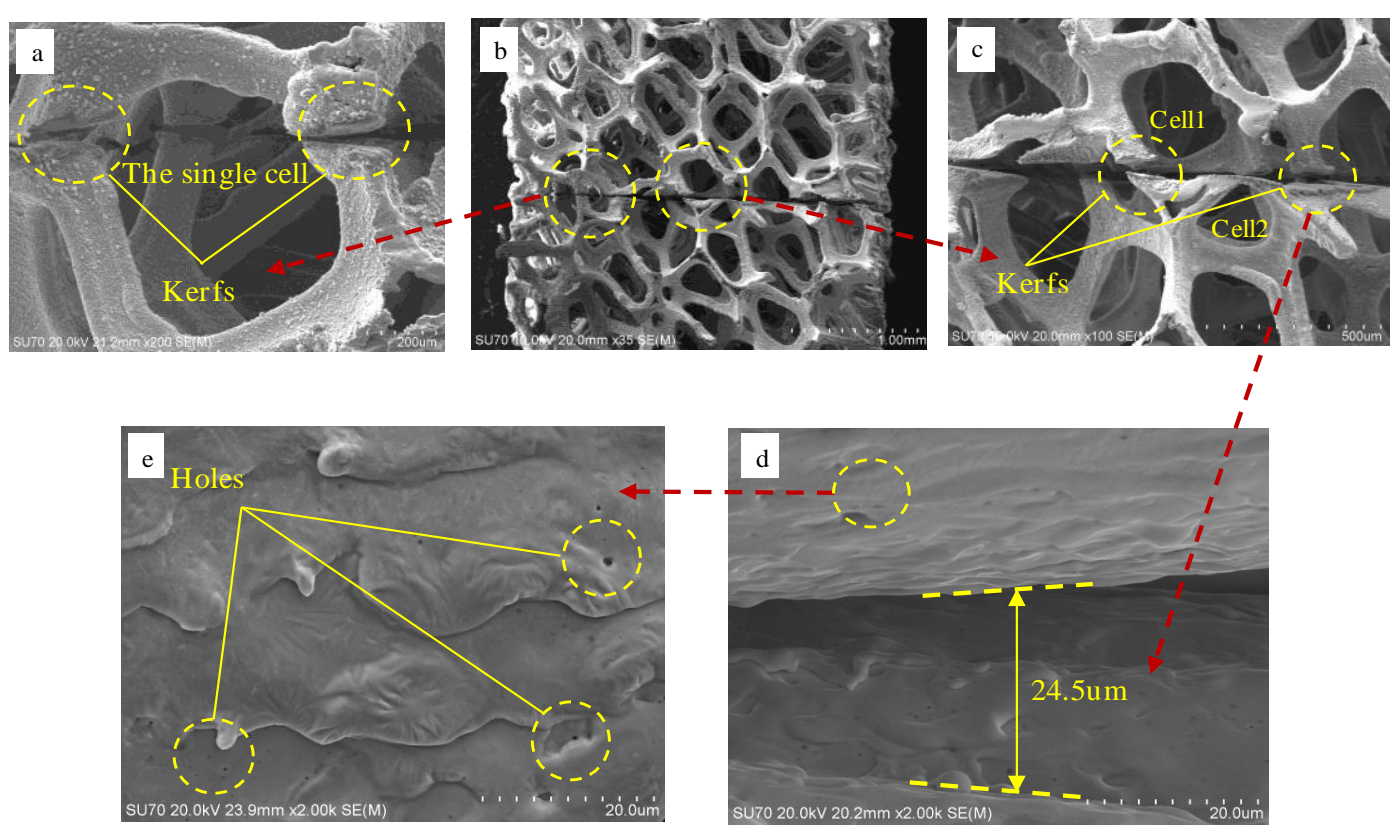

Fig.5 SEM images of a kerf in metal foam using a laser cutting process: (a) kerf passing through a single cell, (b) shape of the kerf with 35X magnification, (c) kerf created on the wall between two cells, (d) shape of the kerf with 2000X magnification, and (e) the surface of the kerf.

\subsection{Cutting sections and appearance of metal foams}

SEM images of cut sections of metal foam using different methods are shown in Fig. 6. From Fig. 6(a), the unprocessed metal foam exhibits a clear porous structure with a uniform distribution. The pore cells have a variety of shapes that are dominated by polygons [28]. A section cut using traditional machining is shown in Fig. 6(b). When the tool is fed from the upper surface to the bottom surface of the metal foam, the walls of the pore cells easily bend or break, and pore structures are destroyed owing to the mechanical stress of the tool. Next, when the cutting tool approaches the worktable, the pore cell walls and pore structure of the metal foam are collapsed and glued together, blocking the pores. With the laser cutting process, the pore shape maintains the original polygon and the structure is nearly unchanged. 
The difference is that there are some smooth sections on the laser cut surface of the cell walls, as shown in Fig. 6(c)-6(e).

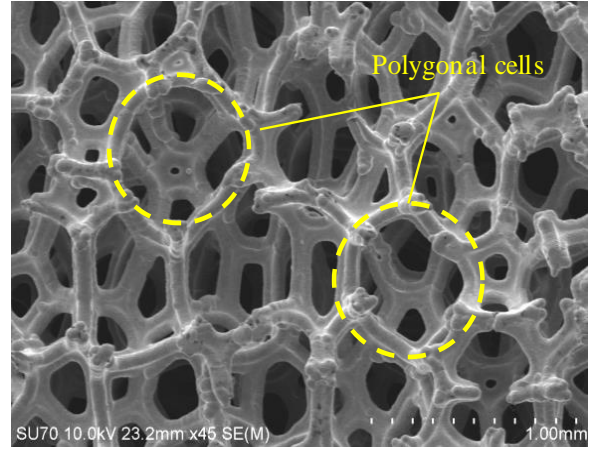

(a) Unprocessed

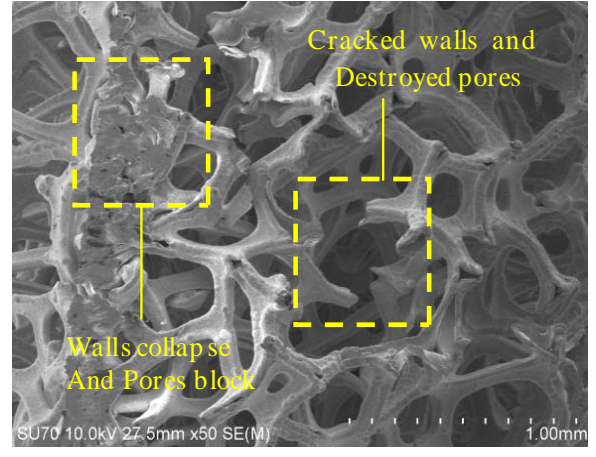

(b) Traditional machining

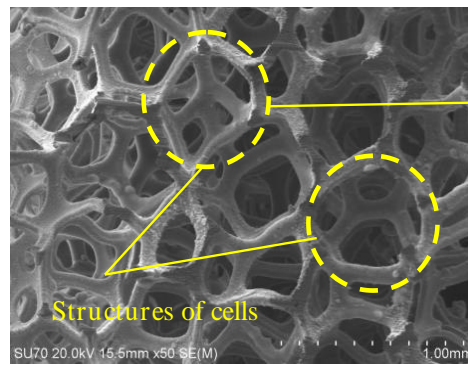

(c) Laser processing

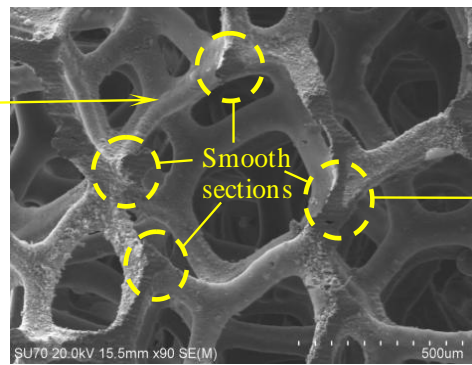

(d) Appearance single cell

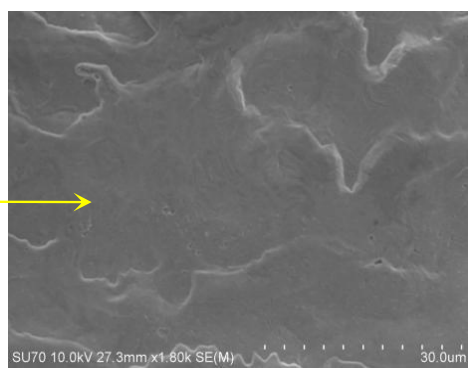

(e) Microstructure of section

Fig.6 SEM images of cut section of unprocessed metal foam, and using traditional machining and laser cutting

Fig.7 shows SEM images of the cutting depths of copper foam cut with different laser output powers of 20,25 , and 30 , a scanning speed of $500 \mathrm{~mm} / \mathrm{s}$, and a pulse frequency of $20 \mathrm{kHz}$. It was found that the cutting depth and kerf width increase with the increase in laser output power. Fig. 8 shows SEM images of the cutting depths, which vary with the scanning speed, using a $30 \mathrm{~W}$ laser output power and a pulse frequency of $20 \mathrm{kHz}$. The cutting depth and kerf width were increased with the decrease in the scanning speed. This is attributed to the increase in the cutting time used to enhance the material removability with a lower scanning speed. Meanwhile, the longer stay time of the thermal and the influence of thermal region can lead to a 
more obvious increase in the kerf width [29].

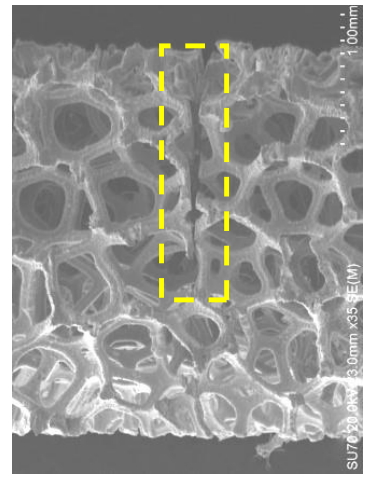

(a) $30 \mathrm{~W}-500 \mathrm{~mm} / \mathrm{s}-20 \mathrm{KHz}$

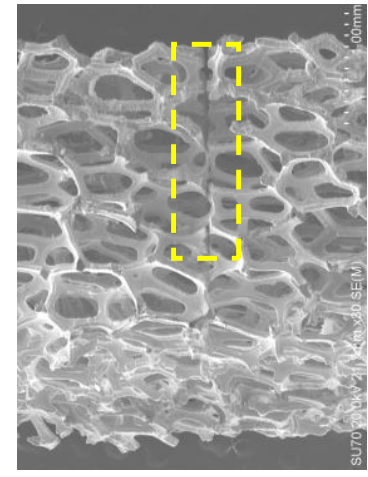

(b) $25 \mathrm{~W}-500 \mathrm{~mm} / \mathrm{s}-20 \mathrm{KHz}$

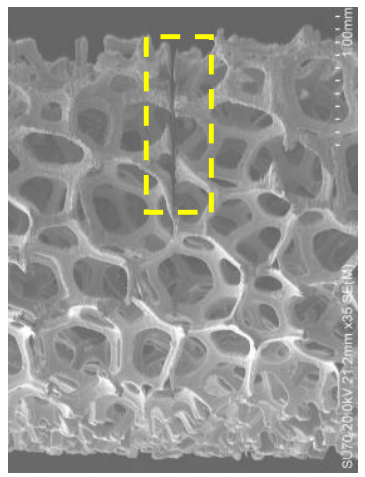

(c) $20 \mathrm{~W}-500 \mathrm{~mm} / \mathrm{s}-20 \mathrm{KHz}$

Fig. 7 SEM images of cutting depth of copper foam with different laser output powers

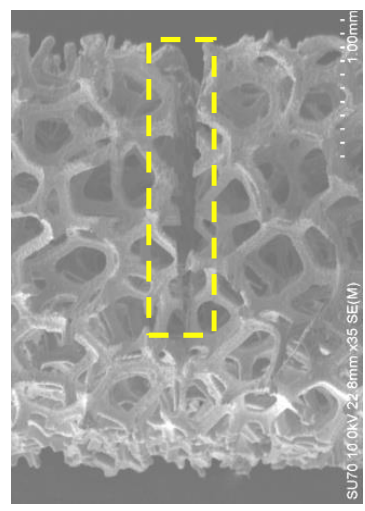

(a) $30 \mathrm{~W}-200 \mathrm{~mm} / \mathrm{s}-20 \mathrm{KHz}$

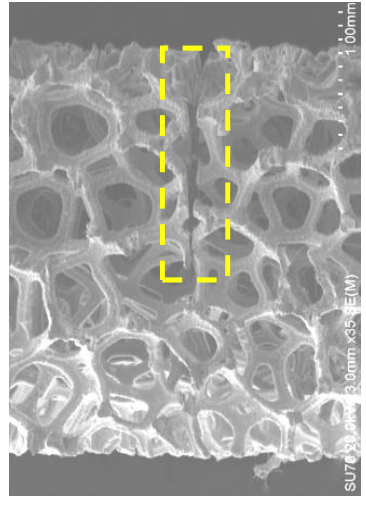

(b) $30 \mathrm{~W}-500 \mathrm{~mm} / \mathrm{s}-20 \mathrm{KHz}$

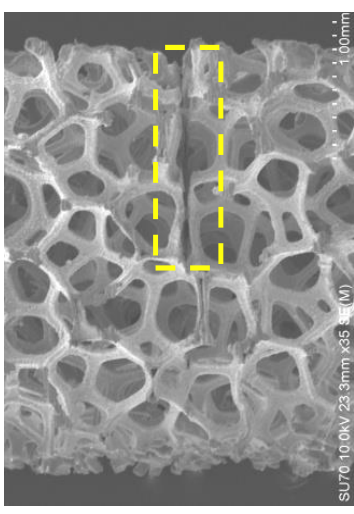

(c) $30 \mathrm{~W}-800 \mathrm{~mm} / \mathrm{s}-20 \mathrm{KHz}$

Fig. 8 SEM images of cutting sections of copper foam with different scanning speeds

The various appearances of copper foam cut using different laser output powers and scanning speeds are shown in Fig. 9. With an increase in laser output power and a decrease in scanning speed, the laser cutting process improves the cutting depth for copper foam, although such improvement will gradually decrease. Adversely, it causes a greater heating effect and wider kerf, which increase the MRR and MOR. Thus, the selection of reasonable processing parameters is critical when cutting metal foam. 


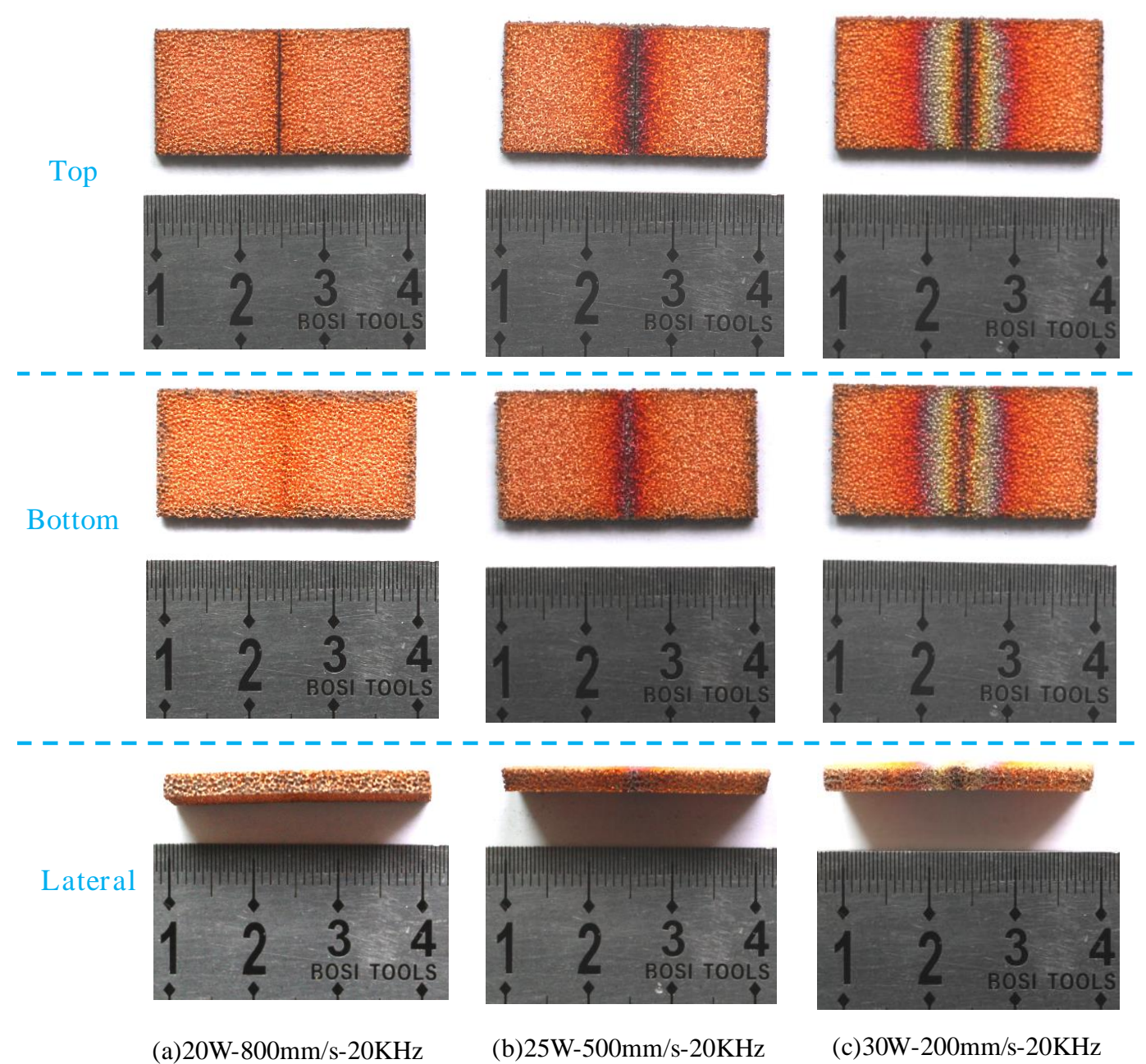

Fig.9 Varying appearances of copper foam with different laser output powers and scanning speeds

\subsection{Effects of processing parameters on material removal rate}

Fig. 10 shows the MRR of metal foam using different processing parameters. For metal foam with different materials, the largest MRR was obtained for ferroalloy foam, and the smallest was obtained for copper foam. Thus, we determined that ferroalloy foam is easy to cut. This is attributed to the absorbance of the different materials. The absorbance of copper is the lowest during the laser cutting process, whereas that of ferroalloy metal is the highest. A lower MRR was obtained with a lower absorbance [30]. Moreover, copper foam has higher thermal conductivity, which makes the material difficult to remove [31]. Hence, the copper foam exhibited 
the lowest MRR. For metal foam with different porosities, the MRR of metal foam with 90 PPI was slightly higher than that of metal foam with 110 PPI. The main reason for this may be that a lower extinction coefficient and higher transmittance of the metal foam with 90 PPI were obtained owing to the fewer pores present [24]. For different processing parameters, the MRR of different metal foams was increased with an increase in the laser output power, as shown in Figs. 10(a) and 10(c). However, the MRR of different metal foams is increased with a decrease in scanning speed, as shown in Figs. 10(b) and 10(d). This is because the material can absorb more energy with a higher laser output power and lower scanning speed during the laser cutting process, and the cutting ability of metal foam is enhanced, thereby increasing the MRR.

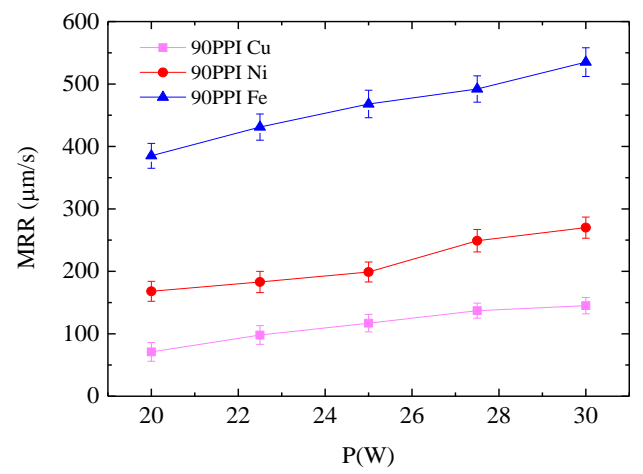

(a) MRR with 90 PPI varies with laser out put powers

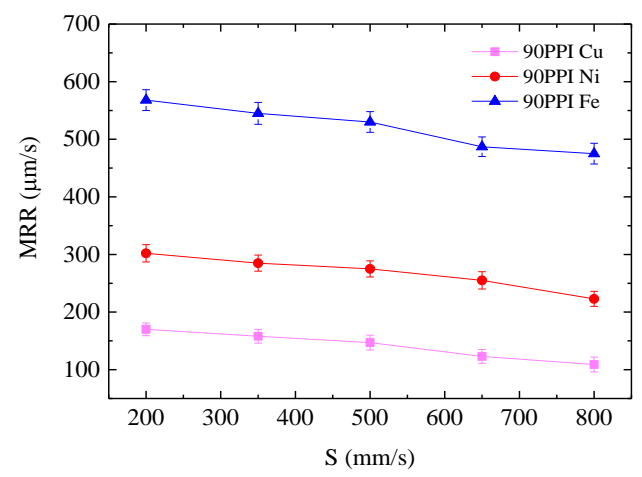

(b) MRR with 90 PPI varies with scanning

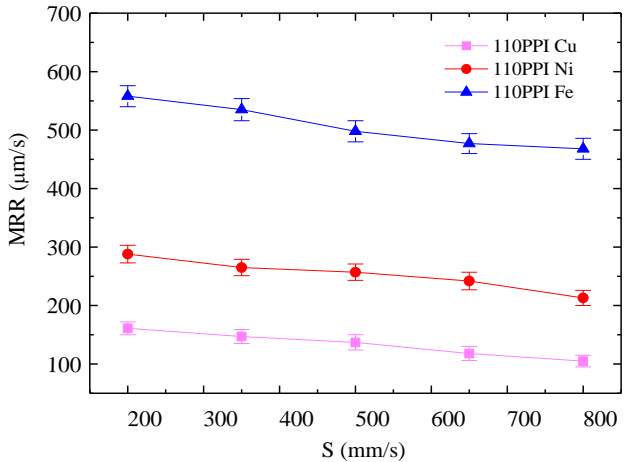

(d) MRR with 110 PPI varies with scanning (c) MRR with 110 PPI varies with laser output powers

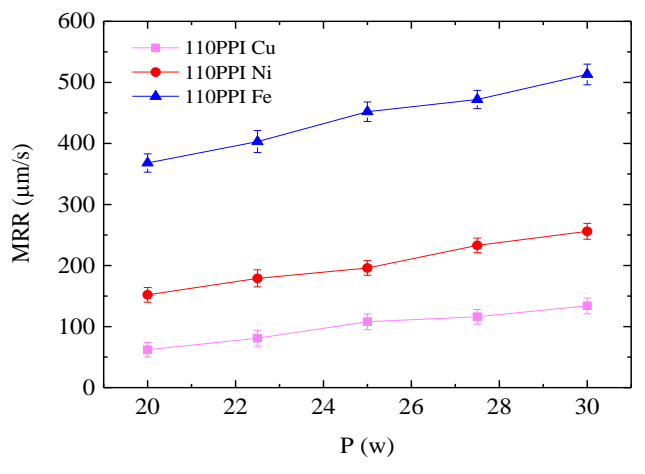

Fig. 10 Variation in material removal rate of metal foam using different processing parameters 


\subsection{Effects of processing parameters on material oxidation rate}

Figs. 11 and 12 show the material oxidation rate of various types of metal foam with 110 PPI using different laser output powers and scanning speeds. On the whole, the ferroalloy foam exhibited the highest MOR, followed by copper foam and nickel foam. It could be that the ferroalloy foam was more easily oxidized at high temperature than the other metal foams. However, some stable metal oxide films are produced during the oxidization process of nickel foam, which can inhibit the nickel foam surface from being oxidized further. Thus, the MOR of nickel foam is the lowest. For the different processing parameters, the MOR of different metal foams was increased with an increase in the laser output power and decrease in the scanning speed, which can be attributed to the temperature increase and extended time of the thermal effects occurring from such changes. In addition, we found that the MOR for 90 PPI is almost as high as for 110 PPI when applying the same type of materials and laser process parameters. Thus, the MOR is not clearly affected by the PPI of the metal foam.

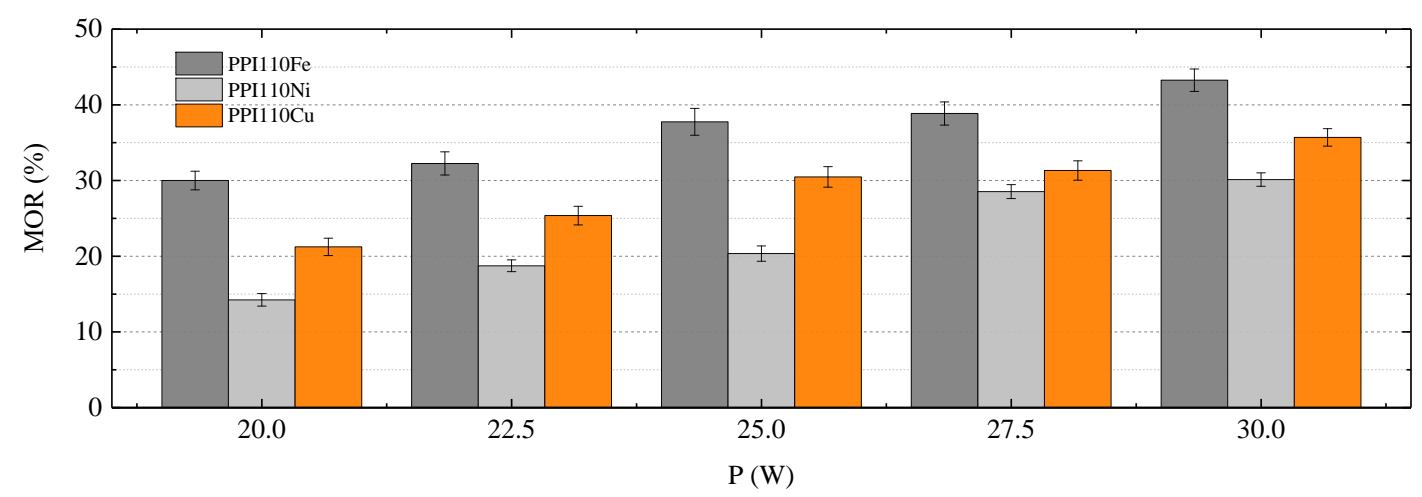

Fig. 11 MOR of 110 PPI metal foam using different laser output powers 


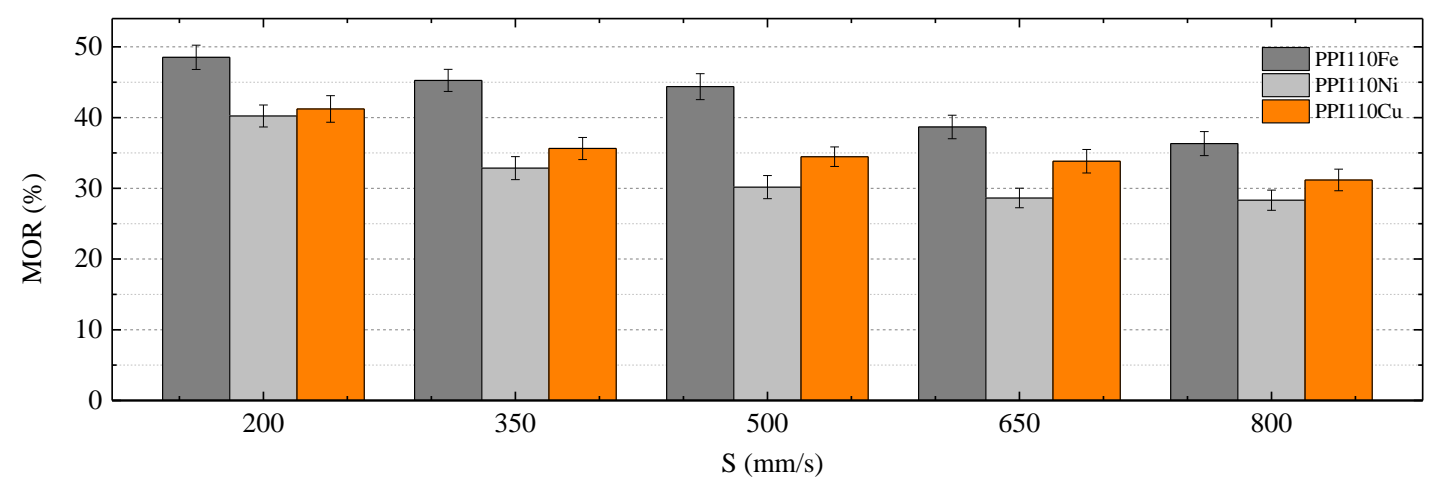

Fig. 12 MOR of 110 PPI metal foam using different scanning speeds

\section{Optimization for processing parameters}

\subsection{Regression equation}

It is assumed that there are $m$ experiment factors, which are independent variables $x_{\mathrm{j}}$, where $j=1,2,3 \ldots m$, and the experiment targets are set to $y_{n}$. The general form of the quadratic regression equation can be expressed as follows:

$\mathrm{y}_{n}=b_{0}+\sum_{j=1}^{m} b_{\mathrm{j}} x_{\mathrm{j}}+\sum_{k<j} b_{k j} x_{k} x_{j}+\sum_{j=1}^{m} b_{j j} x_{j}^{2} \quad k=1,2,3 \ldots, m-1(j \neq k)$

In this experiment, $m$ is 2 .

Based on the above method, copper foam of 110 PPI was selected as the sample material for the laser cutting process. The optimization method of the other metal foam types is similar to the one described here. Based on the CCD, nine experiments were carried out. The MRR and MOR are the experimental targets, which are represented by $y_{1}$ and $y_{2}$, respectively. The experimental results are shown in Table 4 . 
Table 4 Experimental results of central composite experimental design

\begin{tabular}{|c|c|c|c|}
\hline \multicolumn{2}{|c|}{ Experiments } & \multirow{2}{*}{$\frac{\text { Material removal rate }(\mathrm{um} / \mathrm{s})}{\mathrm{y} 1}$} & \multirow{2}{*}{$\frac{\text { Material oxidation rate (\%) }}{\mathrm{y} 2}$} \\
\hline Numbers & Symbols & & \\
\hline 1 & $\mathrm{P}_{-1} \mathrm{~S}_{-1}$ & 65 & 21.67 \\
\hline 2 & $\mathrm{P}_{-1} \mathrm{~S}_{1}$ & 55 & 17.61 \\
\hline 3 & $\mathrm{P}_{1} \mathrm{~S}_{-1}$ & 156 & 45.28 \\
\hline 4 & $\mathrm{P}_{1} \mathrm{~S}_{1}$ & 102 & 26.42 \\
\hline 5 & $\mathrm{P}_{0} \mathrm{~S}_{-1}$ & 117 & 35.83 \\
\hline 6 & $\mathrm{P}_{0} \mathrm{~S}_{1}$ & 81 & 23.54 \\
\hline 7 & $\mathrm{P}_{1} \mathrm{~S}_{0}$ & 134 & 36.83 \\
\hline 8 & $\mathrm{P}_{-1} \mathrm{~S}_{0}$ & 62 & 21.59 \\
\hline 9 & $\mathrm{P}_{0} \mathrm{~S}_{0}$ & 108 & 29.63 \\
\hline
\end{tabular}

The quadratic regression equations can be established based on the results of the CCD experiments, and the parameters of Eq. (5) can be calculated using the following:

$$
\begin{gathered}
b_{j}=\frac{\sum_{k} x_{k j} y_{k}}{\sum_{k}\left(x_{k j}\right)^{2}} \\
b_{i j}=\frac{\sum_{k} x_{k i} x_{k j} y_{k}}{\sum_{k} x_{k i} x_{k j}} \quad(i \neq j) \\
b_{j j}=\frac{\sum_{k}\left(x_{k j}^{2}-\frac{1}{N} \sum_{k}^{N} x_{k j}^{2}\right) y_{k}}{\sum_{k}\left(x_{k j}^{2}-\frac{1}{N} \sum_{k}^{N} x_{k j}^{2}\right)^{2}} \\
b_{0}=\bar{y}-\frac{1}{N} \sum_{j=1}^{\mathrm{m}} b_{j j} \cdot \sum_{k} x_{k j}{ }^{2}
\end{gathered}
$$

where $N$ is the total number of experiments, and $\bar{y}_{\text {is }}$ the average value of nine experimental results.

Thus, the quadratic regression equations of MRR and MOR can be expressed as 
follows:

$$
\begin{aligned}
& \hat{y}_{1}=-306.481+23.3333 P+0.18703 S-0.00733 P S-0.25333 P^{2}+0.000059 S^{2} \\
& \hat{y}_{2}=-68.9593+5.68866 P+0.05275 S-0.00247 P S-0.05733 P^{2}-0.000011 S^{2}
\end{aligned}
$$

Statistical Analysis. 3D surface plots of MRR and MOR can be established by combining regression Eqs. (10) and (11), as shown in Fig. 13. The MRR increases with an increment in the laser output power and a decrement in the scanning speed. The same variation was also observed for the MOR. Therefore, the single optimum condition is the one that provides a higher MRR with an improved MOR. Summarizing the results from Fig. 13, it was found that the laser output power has a more significant effect on the MRR, and the scanning speed has a more significant effect on the MOR.

Analysis of variance (ANOVA) results for the MRR and MOR are shown in Table 5. A statistical analysis of each response was conducted for a $95 \%$ confidence level, where the $R^{2}$ of each response is $97 \%$, which indicates that these models have a high level of statistical significance and a good degree of fitting. From Table 5 (MRR), the $p$-values for all factors are smaller than 0.05 except for the last one, $S^{2}$. This shows that the laser output power and the scanning speed significantly affect both the MRR and the interaction $P^{*} S$. In addition, the $p$-values for $S$ are smaller than for $P$. This shows that the laser output power has a greater effect than the scanning speed for the MRR, which is consistent with the above conclusion. As indicated in Table 5 (MOR), the $p$-values for all factors are smaller than 0.05 , and the $p$-value for 
$S$ is smaller than that for $P$. These results clearly show that the main parameter affecting the MOR is the scanning speed.
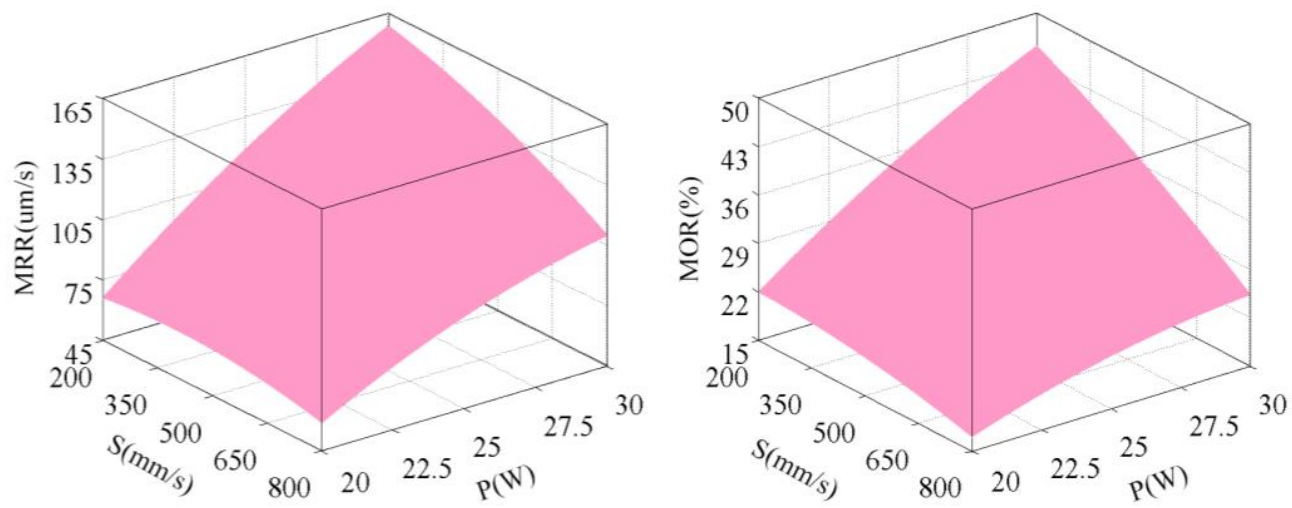

Fig. 13 Material removal rate and material oxidation rate of 3D surface varying with different laser processing parameters

Table 5 ANOVA results for material removal and material oxidation rates

\begin{tabular}{|c|c|c|c|c|c|}
\hline Source & $t$ Stat & $p$-value & Source & $t$ Stat & $p$-value \\
\hline \multicolumn{3}{|c|}{ MRR } & \multicolumn{3}{|c|}{ MOR } \\
\hline$P$ & 6.171664 & 0.008968 & $P$ & 5.512937 & 0.011753 \\
\hline$S$ & 6.018875 & 0.009191 & $S$ & 6.322404 & 0.007999 \\
\hline$P * S$ & -8.16538 & 0.003842 & $P * S$ & -10.2289 & 0.001992 \\
\hline$P^{2}$ & -3.32431 & 0.044909 & $P^{2}$ & -2.79942 & 0.067886 \\
\hline$S^{2}$ & -1.87338 & 0.157724 & $S^{2}$ & -2.80193 & 0.067744 \\
\hline \multicolumn{3}{|c|}{ Note: $F=246.82$, } & \multicolumn{2}{|c|}{ Note: $F=265.53$, } & $\mathrm{R}^{2}=0.9977$ \\
\hline \multicolumn{6}{|c|}{$F_{0.01}(6,2)=10.92$} \\
\hline
\end{tabular}

Optimized parameters. For optimum efficiency, the MRR is expected to increase quickly with a slow increase in the MOR, and using contour plots of the MRR and MOR, as shown in Fig. 14. As Fig. 14(a) indicates, the MRR increases more efficiently with a laser output power of below $26 \mathrm{~W}$. For example, when the laser output power increases from 22 to $26 \mathrm{~W}$, the MRR increases from about 90 to $130 \mathrm{~mm} / \mathrm{s}$. However, when the laser output power increases from 26 to $30 \mathrm{~W}$, the 
MRR increases from about 130 to $150 \mathrm{~mm} / \mathrm{s}$. It seems that the influence of the laser output power diminishes the softening effect above this point. Thus, the optimum laser output power is considered to be around 26 W. As shown in Fig. 14(b), the MOR decreases more efficiently with a scanning speed above $400 \mathrm{~mm} / \mathrm{s}$ at a laser output power of $26 \mathrm{~W}$. However, the MOR decreases slowly with a rapid drop in the MRR at a scanning speed of above $500 \mathrm{~mm} / \mathrm{s}$. Comparing the scanning speed of 200 to 500 $\mathrm{mm} / \mathrm{s}$ with that of 500 to $800 \mathrm{~mm} / \mathrm{s}$, the increase in the MRR declines by about 3-fold. Thus, the optimized parameters can be confirmed as an laser output power of around $26 \mathrm{~W}$ and a scanning speed ranging from 400 to $500 \mathrm{~mm} / \mathrm{s}$.

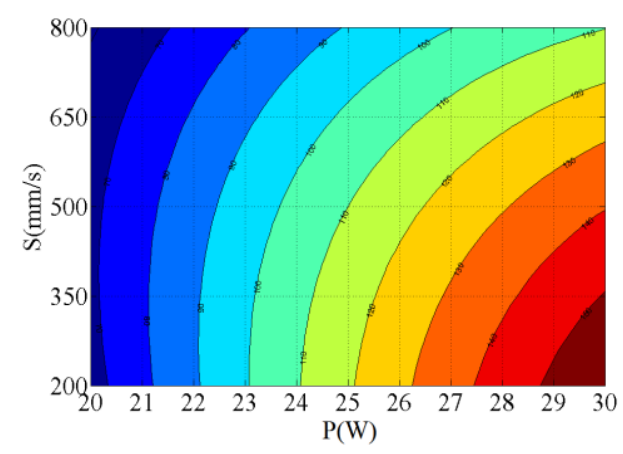

(a) Contour plots of MRR

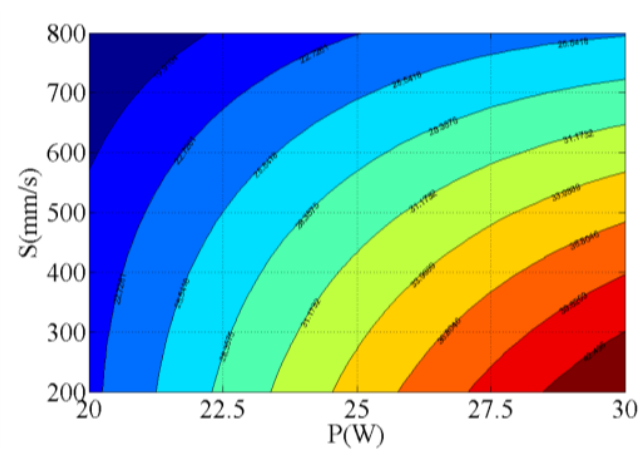

(b) Contour plots of MOR

Fig. 14 Contour plots of (a) MRR and (b) MOR with varying laser processing parameters

\subsection{Processing metal foam samples using optimized parameters}

The optimization parameters for the laser processing of metal foam are confirmed to be a laser output power of $26 \mathrm{~W}$ and a scanning speed of $475 \mathrm{~mm} / \mathrm{s}$. Copper foam of 110 PPI with a $\varnothing 40 \mathrm{~mm}$ diameter and $40 \times 70 \mathrm{~mm}^{2}$ rectangular shape was selected as the processing sample. These metal foam samples with different shapes can be used in a methanol reforming hydrogen reactor as catalyst carriers [32, 33]. Owing to the larger surfaces of these samples than those of the previous 
experimental samples, the kerf width was set to $0.1 \mathrm{~mm}$. The appearance of the processed copper foam samples using the proposed laser cutting process and the optimized parameters are shown in Fig. 15. It was found that copper foam with a regular shape such as a circle or rectangle can be successfully cut using a short processing time (about $5 \mathrm{~min}$ ) when applying the optimized parameters.

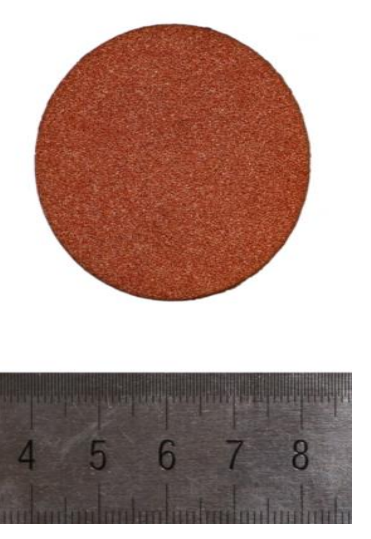

(a) circle sample

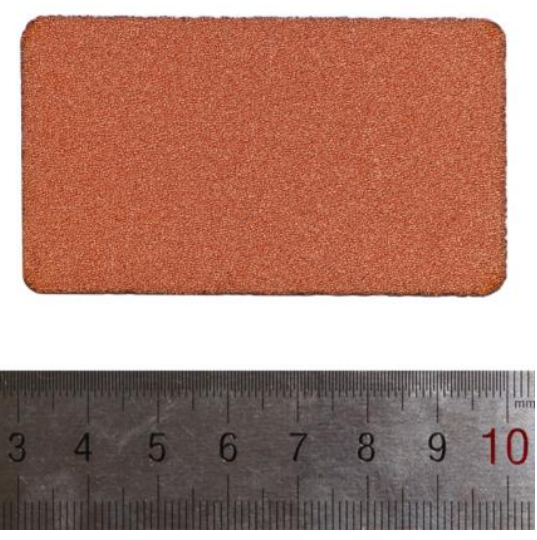

(b) rectangle sample

Fig. 15 Appearance of processed copper foam samples using proposed laser cutting process and optimized parameters

\section{Conclusions}

A laser cutting process was used to efficiently and directly cut metal foam into regular shapes. After the laser cutting process of metal foam was analyzed, the effects of the different materials and PPI on the cutting process were investigated in detail. The main conclusions are as follows:

(1) Metal foam made of copper, ferroalloy, or nickel can be effectively formed into regular shapes using the proposed direct laser cutting process. The laser cutting method can produce a good cutting section without distortion, bending, or collapse of the pore structure. 
(2) Of the three types of foam, the highest MRR and MOR were observed for ferroalloy foam. Of the two different PPI considered, metal foam of 90 PPI showed a much larger MRR than that of 110 PPI. The MRR and MOR were increased with an increase in laser output power and decrease in scanning speed.

(3) The laser cutting parameters were optimized using the CCD method. When a laser output power of $26 \mathrm{~W}$ and a scanning speed of $475 \mathrm{~mm} / \mathrm{s}$ were selected, copper foam with a good cutting section and a regular shape was obtained.

\section{Acknowledgements}

This work was supported by the National Natural Science Foundation of China (No. 51475397) and the Natural Science Foundation of Fujian Province of China (No.2017J06015). In addition, support from the Fundamental Research Funds for Central Universities, Xiamen University (No. 20720160079), and the Collaborative Innovation Center of High-End Equipment Manufacturing in Fujian are also acknowledged.

\section{References}

[1] Jin H, Fan L, Zhu Z, Yu Z (2017) A pore-scale visualized study of melting heat transfer of a paraffin wax saturated in a copper foam: Effects of the pore size. International Journal of Heat and Mass Transfer 112: 39-44.

[2] Castro G, Nutt SR (2012) Synthesis of syntactic steel foam using mechanical pressure infiltration. Materials Science and Engineering 535: 274-280. 
[3] Ji K, Zhao H, Zhang J, Chen J, Dai Z (2014) Fabrication and electromagnetic interference shielding performance of open-cell foam of a $\mathrm{Cu}-\mathrm{Ni}$ alloy integrated with CNTs. Applied Surface Science 311: 351-356.

[4] Shen CC, Jian TY, Wang YT (2013) Steam Reforming of Methanol in a compact Copper Microchannel Foam Reactor. Fuel Cells 13(6): 965-970.

[5] Giani L, Groppi G, Tronconi E (2005) Mass-Transfer Characterization of Metallic Foams as Supports for Structured Catalysts. I\&EC research 44(14): 4993-5002.

[6] Aartun I, Silberova B, Venvik H, Pfeifer P, Gorke O, Schubert K, Holmen A (2005) Hydrogen production from propane in Rh-impregnated metallic microchannel reactors and alumina foams. Catalysis Today 105(3-4): 469-478.

[7] Muth J, Poggie M, Kulesha G, Michael RM (2013) Novel highly porous metal technology in artificial hip and knee replacement: processing methodologies and clinical applications. Journal of Metals 65: 318-325.

[8] Song Z, Kishimoto S (2006) The cell size effect of closed cellular materials fabricated by pulse current assisted hot isostatic pressing on the compressive behavior. Scripta Materialia 54(8): 1531-1535.

[9] Wang M, Pan N (2008) Modeling and prediction of the effective thermal conductivity of random open-cell porous foams. International Journal of Heat and Mass Transfer 51: 1325-1331.

[10] Billiet M, Schanmpheleire SD, Huisseune H, Paepe MD (2015) Influence of Orientation and Radiative Heat Transfer on Aluminum Foams in Buoyancy-Induced 
Convection. Materials 8: 6792-6805.

[11] Raj ER, Daniel BSS (2008) Manufacturing challenges in obtaining tailor-made closed-cell structures in metallic foams. The International Journal of Advanced Manufacturing Technology 38: 605-612.

[12] Han GL, Li WD (2009) Processing and mechanical properties of magnesium foams. Journal of Porous Materials 16: 251-256.

[13] Ozan S, Bilhan S (2008) Effect of fabrication parameters on the pore concentration of the aluminum metal foam, manufactured by powder metallurgy. The International Journal of Advanced Manufacturing Technology 39(3-4): 257-260.

[14] Tian Q, Guo X (2011) Manufacturing Microporous Foam Zinc Materials with High Porosity By Electrodeposition. Journal of Wuhan University of Technology-Materials Science Edition 26(5): 843-846.

[15] Banhart J (2001) Manufacture, characterization and application of cellular metals and metal foams. Prog. Mater. Sci 46: 559-632.

[16] Kwon YJ, Shigematsu I, Saito N (2008) A novel surface modification process for porous metals using friction phenomena. Materials Letters 62: 4458-4460.

[17] Scott MF, Albert SJ, Jun Q (2004) Investigation of the spark cycle on material removal rate in wire electrical discharge machining of advanced materials. International Journal of Machine Tool \& Manufacture 44: 391-400.

[18] Alexander MM, Dennis K, Norbert J, Kai O (2016) Machining of Metal Foams with varying mesostructure using Wire EDM. Procedia CIRP 42: 263-267.

[19] Zou R, Yu Z, Liu W, Guo M, Li J (2016) Influence of porous structure on the 
machining performance of micro EDM. Journal of Materials Processing Technology 232: 43-51.

[20] Cai C, Tao W, Li L, Chen Y (2015) Weld bead formation and corrosion behavior of pulsed laser welded zirconium alloy. The international Journal of Advanced Manufacturing Technology 77: 621-628.

[21] Zhou W, Ling W, Liu W, Peng Y, Peng, J (2015) Laser direct micromilling of copper-based bioelectrode with surface microstructure array. Optics and Lasers in Engineering 73: 7-15.

[22] Ke W, Zhu D, Cai G (2010) Simulation and Analysis of Spectral Emissivity of Metals. Acta Aeronautica et Astronautica Sinica 31(11): 2139-2145.

[23] Zhao CY, Lu TJ, Hodson HP (2004) Thermal radiation in ultralight metal foams with open cells. International Journal of Heat and Mass Transfer 47: 2927-2939.

[24] Zhang B, Dembinski L, Coddet C (2013) The study of the laser parameters and environment variables effect on mechanical properties of high compact parts elaborated by selective laser melting 316L powder. Materials Science \& Engineering A 584: 21-31.

[25] Peirovi S, Pourasghar M, Nejad Farokhi A, Hassan MA (2017) A study on the different finite element approaches for laser cutting of aluminum alloy sheet. The international Journal of Advanced Manufacturing Technology 93: 1399-1413.

[26] Lacroix M., Nguyen P., Schweich D, Pham HC, Savin PS, Edouard D (2007) Pressure drop measurements and modeling on $\mathrm{SiC}$ foams. Chemical Engineering 
Science 62: 3259-3267.

[27] Li X, Chen J, Liu F, Li X, Zhang Q (2010) PMMA microlens array preparation using carbon dioxide laser. Acta Optica Sinica S1: s100104.

[28] Kaya AC, Fleck C (2014) Deformation behavior of open-cell stainless steel foams. Materials Science \& Engineering A 615: 447-456.

[29] Nisar S, Sheikh MA, Lin L, Safdar S (2010) The effect of material thickness, laser power and cutting speed on cut path deviation in high-power diode laser chip-free cutting of glass. Optics \& Laser Technology 42(6): 1022-1031.

[30] Lin X, Shao T (2001) Lumped Method for the Measurement of Laser Absorptance of Materials. Acta Physica Sinica 50(5): 856-859.

[31] Adrian HAL, Alessandro A, Alessandro F, Luca R (2018) Long-pulse quasi-CW lasercutting of metals. The international Journal of Advanced Manufacturing Technology 94: 155-162.

[32] Zhou W, Ke Y, Wang Q, Wan S, Lind J, Zhang J, Huie KS (2017) Development of cylindrical laminated methanol steam reforming microreactor with cascading metal foams as catalyst support. Fuel 191:46-53.

[33] Yu H, Chen H, Pan M, Tang Y, Zeng K, Peng F, Wang H (2007) Effect of the metal foam materials on the performance of methanol steam micro-reformer for fuel cells. Applied Catalysis A: General 327(1): 106-113. 


\section{Figure captions}

Fig. 1 Schematic of cutting and detection process of metal foam

Fig. 2 Optical image of laser direct cutting process of metal foam

Fig. 3 Schematic of the central composite experimental design

Fig. 4 Schematic of laser cutting process of metal foam: (a) initial stage of cutting, (b) middle stage of cutting, and (c) final stage of cutting

Fig. 5 SEM images of a kerf in metal foam using a laser cutting process: (a) kerf passing through a single cell, (b) shape of the kerf with $35 \mathrm{X}$ magnification, (c) kerf created on the wall between two cells, (d) shape of the kerf with 2000X magnification, and (e) the surface of the kerf

Fig. 6 SEM images of cut section of unprocessed metal foam, and using traditional machining and laser cutting: (a) unprocessed, (b) traditional machining, (c) laser processing, (d) appearance of a single cell, and (e) microstructure of a section

Fig. 7 SEM images of cutting depth of copper foam with different laser output powers: $30 \mathrm{~W}, 500 \mathrm{~mm} / \mathrm{s}, 20 \mathrm{KHz}$, (b) $25 \mathrm{~W}, 500 \mathrm{~mm} / \mathrm{s}, 20 \mathrm{KHz}$, (c) $20 \mathrm{~W}, 500 \mathrm{~mm} / \mathrm{s}, 20 \mathrm{KHz}$ Fig. 8 SEM images of cutting sections of copper foam with different scanning speeds: (a) $30 \mathrm{~W}, 200 \mathrm{~mm} / \mathrm{s}, 20 \mathrm{KHz}$, (b) $30 \mathrm{~W}, 500 \mathrm{~mm} / \mathrm{s}, 20 \mathrm{KHz}$, (c) $30 \mathrm{~W}, 800 \mathrm{~mm} / \mathrm{s}$, $20 \mathrm{KHz}$

Fig. 9 Varying appearances of copper foam with different laser output powers and scanning speeds: (a) $20 \mathrm{~W}, 800 \mathrm{~mm} / \mathrm{s}, 20 \mathrm{KHz}$, (b) $25 \mathrm{~W}, 500 \mathrm{~mm} / \mathrm{s}, 20 \mathrm{KHz}$, (c) $30 \mathrm{~W}$, $200 \mathrm{~mm} / \mathrm{s}, 20 \mathrm{KHz}$

Fig. 10 Variation in material removal rate of metal foam using different processing 
parameters: (a) MRR with 90 PPI varying with laser out power, (b) MRR with 90 PPI varying with scanning speed, (c) MRR with 110 PPI varying with laser out power, and (d) MRR with 110 PPI

varying with scanning speed

Fig. 11 MOR of 110 PPI metal foam using different laser output powers

Fig. 12 MOR of 110 PPI metal foam using different scanning speeds

Fig. 13 Material removal rate and material oxidation rate of 3D surface varying with different laser processing parameters: (a) 3D surface plot of MMR, (b) 3D surface plot of MOR

Fig. 14 Contour plots of (a) MRR and (b) MOR with varying laser processing parameters

Fig. 15 Appearance of processed copper foam samples using proposed laser cutting process and optimized parameters: (a) circle sample, (b) rectangle sample 


\section{Table captions}

Table 1 Specifications of characteristic parameters of the fiber laser system applied

Table 2 Pore size and chemical composition of foam metals

Table 3 Parameters of central composite experimental design

Table 4 Experimental results of central composite experimental design

Table 5 ANOVA results for material removal and material oxidation rates 